\title{
How Does Organizational Climate Influence The Ethical Behavior Of People In An Organization?
}

Almerinda Forte, (E-mail: fortea@stjohns.edu), St. John’s University

\begin{abstract}
Litwin constructed a questionnaire to measure organizational climate. At the same time working independently, Tagiuri investigated how executives perceived the environment in which they functioned. Litwin and Tagiuri reached the same conclusion: organizational climate influences the behavior of people in an organization (McKenna, 1993, p 37).

Litwin and Stringer (1968) developed an instrument to collect perceptions of organizational environment. They contended that realities of an organization are understood only as they are perceived by members of the organization (p.42). Litwin and Stringer defined organizational climate operationally as the sum of perceptions of individuals working in the organization (.p. 66) Climate, according to Litwin and Stringer, influences organizational decisions by creating certain kinds of beliefs about what kind of consequences will follow from various actions . (Litwin \& Stringer 1968, p. 188) Of importance to this paper was their conclusion that organizational climate properties can be perceived by members of an organization and reported on by them on an appropriate questionnaire. (p. 187). This conclusion forms a critical assumption for this paper.
\end{abstract}

The organizational work climate reviewed in this paper is based largel on the research conducted by Tagiuri, Litwin, and Sringer in 1968; Mauro in 1987; Victor and Cullen in 1987 and 1988; McKenna in 1993; Wyld in 1993; D'Aquila in 1997 and Forte in 2001.

B usiness ethics, especially practiced by managers, concern both the general public and business community. As a result, attention has increased on corporate individuals' development of moral reasoning. Past research on individual and business ethics, as well as the theoretical models that attempt to explain business decision behavior, indicate that organizational-level variables have a significant impact on individual decisions. Since managers' decisions impact organizational goals and organizational ethical behavior, this researcher investigated the degree of difference in the moral reasoning ability between business managers of selected industries as well as the differences between top, middle, and first-line management levels.

Litwin constructed a questionnaire to measure organizational climate. At the same time working independently, Tagiuri investigated how executives perceived the environment in which they functioned. Litwin and Tagiuri reached the same conclusion: organizational climate influences the behavior of people in an organization (McKenna, 1993, p. 37).

Litwin and Stringer (1968) developed an instrument to collect perceptions of organizational environment. They contended that realities of an organization are understood only as they are perceived by members of the organization (p. 42). Litwin and Stringer defined organizational climate operationally as the sum of perceptions of individuals working in the organization (p. 66). Climate, according to Litwin and Stringer, influences organizational

Readers with comments or questions are encouraged to contact the author via email. 
decisions by creating certain kinds of beliefs about what kind of consequences will follow from various actions. (Litwin \& Stringer 1968, p. 188). Of importance to this research was their conclusion that organizational climate properties can be perceived by members of an organization and reported on by them on an appropriate questionnaire. (p.187). This conclusion forms a critical assumption for this research.

The organizational work climate reviewed here is based largely on the research conducted at the Tagiuri, Litwin, and Stringer in 1968; Mauro in 1987; Victor and Cullen in 1987 and 1988; McKenna in 1993; Wyld in 1993; D'Aquila in 1997.

Tagiuri and Litwin co-wrote in 1968, Organizational Climate, Exploration of a Concept while Litwin and Stringer were the co-authors of Motivation and Organizational Climate. The authors of both books were from the Harvard University's research division of the Graduate School of Business.

Mauro's (1987) research concerned the clash between ethics and the profit motive. Mauro's study investigated the difficulty that some managers experience when making decisions without involving ethical considerations. The organization's climate was identified in the study as having an influence on ethical decisionmaking. Mauro also found that pressure was exerted on employees to compromise personal standards of ethics to meet company demands of profits. His research findings support the idea that corporate culture must include business ethics.

Mauro found that pressures from performance measurements are critical barriers to ethical decisionmaking. Mauro wanted to gain insight into the unique relationship of business ethics, managerial decision-making, and organizational values and culture. This research used the ethics case study method within a single corporation. The multibillion dollar high telecommunications/computer corporation which was selected for the study held an impeccable reputation for high ethical standards. The Chief Executive Office (CEO) in October 1984 granted permission for Mauro's study. Participants were selected from functional areas within the organization and had responsibilities for making decisions that dealt with ethical dilemmas. Intensive interviews were conducted with 21 participants, who responded to an 18 question interview schedule. The participating sample was comprised of a cross section of managers from third level to officer level. Mauro conducted four explanatory interviews to acquire information on business ethics. Mauro focused on the perceptions of financial officers of their firm's organizational climate as it related to financial statements reporting situations and the resolutions of these situations.

The results of this study support the notice that an organization's ethical climate influences the decisionmaking process of employers when confronted with ethical dilemmas. This study supports the need for this researcher to examine the relationship between perceived organizational climate and the moral reasoning of managers.

Victor and Cullen (1987) studied the linkage between corporate ethical standards and organizational behavior. Victor and Cullen developed an instrument designed to measure perceptions of ethical climate by members of an organization. They extended Kohlberg's theory of moral development to organizations. Victor and Cullen assumed that corporate ethical climates evolved in a dimension similar to Kohlberg's moral reasoning levels for individuals. They classified organizations into categories (Caring, Law and Code, Rule, Instrumental, and Independence) of distinct ethical climate types. Victor and Cullen realized that individuals adapt to their environment by learning the appropriate expected behavior through climate perceptions (1987, p. 53). They concluded that corporations have distinct ethical climate types, that climate types influence managerial behavior, and that climate types influence what ethical conflicts are considered and the process by which the conflicts would be resolved.

This study used Victor and Cullen's ethical climate construct to determine the relationship of perceived organizational ethical work climate types and the moral reasoning of individual managers.

McKenna's (1993) research investigated fraudulent financial reporting by certified and noncertified management accountants in organizations with perceived different ethical work climates. McKenna used the ethical 
climate construct of Victor and Cullen for his theoretical framework. Senior-level executives of the Crain 600 publicly held companies served as subjects for the study and were surveyed by a mail questionnaire.

The results of McKenna's study found that the first most identified perceived organization climate was Law and Code, or 57 percent of all returns out of a total of 185 responses. A Rule climate was the second most frequently identified perceived organizational climate type representing 19 percent or 35 out of a total of 185 returns. Eight percent of all returns (15 of 185) reflected a Caring type of perceived organizational climate, and four percent ( 8 of 185) reflected an Instrumental type of perceived organizational climate.

What McKenna concluded from his study was that individual CPAs in industry considers themselves as an employee first and a professional second. What McKenna also concluded from the study is that the salaried CPA's loyalty to the employer is as strong as the salaried non-professional's loyalty. The study may have determined that the commitment of the salaried CPA to the organization of employment is one of dependence. McKenna's research originally assumed but did not find that certified accountants would take a stronger course of action to resolve ethical situations than noncertified accountants.

Overall respondents indicated that, in general, their organizations were law abiding, focusing on law and code. The respondents also indicated that their organizations strived to insure that reporting procedures of financial statements were sound. The senior executives surveyed also believed that their companies were striving to operate in an ethical manner.

Wyld (1993) investigated three key propositions supporting the Synthesis Integrated Mode (SIM) of Ethical Decision Making in Business, which was developed by Ferrell, Gresham, and Fraederich (1989). Wyld's research tested the role of cognitive moral development in ethical decision making. This was done by exploring whether Victor and Cullen's $(1987,1988)$ typology of ethical work climates would prove to act as an authorized agent to clarify the cultural influence of the organization on individual ethical attitude and behavior. Wyld used a nonrandom purposive sample for his survey, which consisted of MBA students and graduating, senior-level BBA students at a number of colleges of business administration in the southern United States. The sample totaled 294 full-time employed subjects.

Wyld's research found implications for the five-fold typology of ethical climate types that three of the five climate types (Law and Code, Rule, and Instrumental) proved to be very useful indicators of micro-level ethical attitudes and behavior. However, he found that Caring and Independent types proved to be ineffectual at this task. Wyld suggests that the three functional climate types can be regarded as useful constructs for both further theory development and empirical research in this area.

Wyld's research concluded that ethical attitudes were related to ethical intentions and that these ethical intentions were associated with judgments of the ethicalness of a decision. He found no consistent relationships between the cognitive moral development of an individual and his/her ethical attitudes and behavior.

D'Aquila (1997) examined how a controlled environment would affect financial accountants at selected management levels decisions-making processes when confronted with ethical dilemmas that may affect financial reporting decisions. The Lewin's Force Field Analysis and Ferrell and Grasham's Contingency Framework for Understanding Ethical Decision Making provided the conceptional rationale for this study. The researcher surveyed 400 CPA's. The results showed that respondents who perceive a tone at the top in their organization that supports ethical behavior were more likely to fairly report financial information. The study also found that codes of conduct and pressure for short-term performance had no significant effect on financial reporting decisions. Respondents in general perceived a strong tone at the top of their organizations supporting ethical behavior. Strong codes of conduct and more pressure for short term targets were more likely to be apparent by respondents in large and publicly held organizations. The results of this research indicate that managers' integrity and ethical values impact the employees' decision-making process. The results also support the concept that corporate culture must include business ethics. This study supports the notion that managers, especially top managers, set the tone of the organizations ethical values and behavior. Organizational climate influences the decision-making processes of employees when confronted with ethical dilemmas. 
This researcher studied how the perceived ethical climate of a manager's organization related to the moral reasoning of individual managers on various levels. By investigating the available literature, this researcher examined the strengths, validity, and reliability of the instruments used in conducting research on business ethics.

Kohlberg's theory of moral development provided the theoretical rationale for the research study, and James Rest's Defining Issues Test (DIT) was used to determine managers' moral development level. According to Rest, ethical development progresses in stages. Individuals may advance to higher moral stages only if they can cognitively assimilate such thinking. However, individuals may occasionally exhibit thinking indicative of lower stages as well. The DIT was administered to the sample in written questionnaire form. The benefits of a written questionnaire include the elimination of interviewer bias, the expeditions and simultaneous administration to a large audience, and the operationalization of the ethical stages concept.

The ethical work climate theory of Victor and Cullen helped determine the impact that corporate culture has on individual managers' moral reasoning ability in selected industries. Victor and Cullen concluded that the perceived ethical climate has an influence on the types of ethical conflicts considered and the process by which such conflicts are resolved (McKenna, 1993, p. 32). Victor and Cullen's theory was used to determine the following: the degree to which there is a relationship between self-reported corporate climate influences and the moral reasoning of top, middle and first-line management, and the degree to which the corporate climate relates to a manager's locus of control with respect to moral reasoning ability.

Rotter's theory of internal-external locus of control evolved from Carl Jung's work. In Psychological Types (1923), Jung defined two opposing tendencies in personality: introversion and extroversion. While both tendencies are present in all individuals, one tends to dominate the other. In this study the researcher investigated the relationship between managers' locus of control and their moral reasoning ability. Also, the selected demographic and institutional variables (age, work tenure, education, gender, management level and industry category) provided the useful information to investigate.

A review of the literature suggested that various demographic and institutional variables have the potential to impact moral reasoning. Little is known about the connection between ethical climate, locus of control, and principled moral reasoning. Little research has been conducted linking the frameworks together; thus it seemed like an appropriate opportunity to investigate such relationships.

This researcher set out to determine the degree to which a relationship existed between ethical climates, locus of control, and principled moral reasoning. In addition, other demographic and institutional variables were analyzed to assess what, if any, relationship these variables had with principled moral reasoning. (See figure 1).

The researcher measured principled moral reasoning with the Defining Issues Test developed by James Rest. The short form of the DIT (3 scenarios vs. 6 in the longer version) was used in this study. Rotter's I-E Scale, a 29 item forced choice instrument, was used to measure a respondent's internal orientation or external orientation. Victor and Cullen's categories of distinct ethical climate types (Caring, Law and Code, Rules, Instrumental, and Independence) were defined, including descriptors, on the survey questionnaire and participants were asked to choose the perceived organizational ethical work climate, which in their perception, best define their organization.

A random sample of 400 managerial and executive level employees at a variety of Fortune 500 firms throughout the United States served as subjects for the study. Dun \& Bradstreet (D\&B), a well-known and respected provider of financial information and business services, with a database of ten million different-sized companies, drew the random sample for this study. D\&B provided the researcher with a proportional stratified random sample of 400 managerial and executive level employees at a variety of organizations throughout the United States. The job titles included in this search were those at the managerial levels and those at the executive levels.

Organizations with Standard Industrial Classification (SIC) codes, which relate to agriculture, forestry, fishing, mining or construction were excluded from this study; these organizations tend to have different organizational structures from the traditional top, middle, and first-line management types. Also, organizations 
whose SIC codes relate to governmental agencies were excluded from this study. These agencies employ many civil servants or appointed employees, and as the foregoing, these types of organizations tend to have different organizational structures from the traditional top, middle, and first-line management.

Data collection was accomplished via the mailing of a survey research instrument consisting of the short form of the DIT, Rotter's I-E Scale, a Demographic and Institutional Questionnaire, and Victor and Cullen's Five Ethical Climate Types Defined. Dillman's Total Design Method (TDM) was employed and anonymity was assured. The TDM entailed utilizing an advance notice letter, followed by a mailing which included a cover letter, the research instrument, and anonymous response card, and then two follow-up mailings. A total of 400 questionnaires were mailed. Of the 224 received questionnaires, 10 were discarded because of errors or inconsistencies, resulting in 214 useable questionnaires, for a response rate of 58\% and a usable response rate of 55\%.

The researcher found a number of statistically significant relationships. For instance, a statistically significant relationship between age and organizational ethical climate types (Caring, Law and Code, Rule, Instrumental, and Independence) was found as well as a statistically significant relationship between management levels and organizational ethical climate. In addition, other statistically significant relationships were revealed, including that between the manufacturing industry's "P" scores and the service industry's "P" scores, tenure and ethical climate types, education and ethical climate types, and selected demographics (industry types and gender) and moral reasoning.

However, this study also found a number of relationships that were not statistically significant. For instance, no significant difference was found between a manager's internal locus of control and his/her moral reasoning; neither was there a significant difference between age and the moral reasoning ability of individual managers nor between work tenure and moral reasoning. Similarly, this study found no statistically significant relationship between education and moral reasoning.

There was no statistically significant relationship between the transportation, communication, and utilities industry, wholesale and retail industry and the finance, insurance, and real estate industry, and the moral reasoning ability of individual managers.

Although female respondents reported a higher mean "P" score than male respondents, this study did not find a statistically significant relationship between male and female "P" scores. No statistically significant relationship was found between perceived organizational ethical climate types (Caring, Law and Code, Rule, Instrumental, and Independence) and the moral reasoning ability of individual managers. This study also found no statistically significant relationship between a manager's locus of control and selected demographics (age, work tenure, management levels, and education), or between an individuals' perceived organizational ethical work climate type (Caring, Law and Code, Rule, Instrument, and Independent) versus moral reasoning. In summary, of the twelve hypotheses tested, only seven were supported.

Conclusions and Implications drawn from the findings of this study. This section will outline the conclusions and implications drawn from the statistically significant relationships.

\section{Finding One}

A statistically significant relationship was found between age and organizational ethical climate types (Caring, Law and Code, Rule, Instrumental, and Independence).

The majority of the respondents, 134 or $62.6 \%$, who perceived their organizational ethical work climate type as Rule, reported a mean age of 47 . The 16 respondents or $7.5 \%$ who perceived their organizational ethical climate type to be Caring and the 38 respondents or $17.8 \%$ who perceived their organizational ethical climate type to be Law and Code reported a mean age of 44 . The six respondents or $2.8 \%$ who perceived their organizational ethical climate type to be Instrumental reported a mean age of 52, while the 20 respondents or $9.3 \%$ who perceived their organizational ethical climate type to be Independent reported a mean age of 51. 
McKenna's (1993) research investigated fraudulent financial reporting by certified and noncertified management accountants in organizations with perceived different ethical work climates. He used the ethical climate construct of Victor and Cullen for his theoretical framework. The results of McKenna's study found that the first most identified organization was Law and Code, or 57\% of returns out of a total of 185 responses. A Rule climate was the second most frequently identified organizational climate type, representing $19 \%$ or 35 out of a total of 185 returns. Eight percent, or 15 of 185 returns, reflected a Caring type of organizational climate, and 4\%, or 8 of 185 returns, reflected an Instrumental type of organizational climate. Slightly different from McKenna's study, this study found that the first most identified ethical organizational climate type was Rule, or $62.6 \%$ of returns, or 134 of 214 responses. Law and Code was the second most frequently identified organizational climate type, at $17.8 \%$ or 38 of 214 returns and an Independence type of organizational climate was reported on $9.3 \%$ of returns or 20 of 214 responses. A Caring type of organizational climate was reported on 7.5\% of returns, or 16 of 214 returns, and $2.8 \%$ or 6 of 214 returns reflected an Instrumental type of ethical organizational climate.

The researcher in this study found a statistical significance between age and perceived organizational ethical climate type. Age versus ethical climate types had a statistical significance in this study, $\mathrm{F}=1.981$, and $\mathrm{p}$ value .002. Slightly different from McKenna's study, this study reports that the first most identified ethical organizational climate type was Rule, followed by Law and Code, Independence, Caring, and Instrumental. What the results show is that the younger mean ages 44 (Caring), 45 (Law and Code), and 47 (Rule) are associated with the more ethical organizational climate types. McKenna's study found that the first most identified organization was Law and Code, followed by Rule, Independence, Caring, and Instrumental respectively.

Since the older managers and executive level employees have more work experience than the younger employees, they may have suffered more disappointments in their work career which may have affected their perception of their organizational ethical work climate. Managers and executive level employees of any age, especially older managers, could possibly benefit from training interventions geared to refocus their thought processes in a more ethically attuned direction.

The implication of this finding, regarding business education, reinforces the concept that business ethics should continue to be strongly emphasized in business curricula. All business subjects, including accounting, management and marketing, should challenge students with ethical dilemmas and moral reasoning issues. This will help emphasize that ethical soundness is of vital importance in corporate America.

A statistically significant relationship was found between management levels and organizational ethical climate; the $\mathrm{F}$ ration was 4.773 and $\mathrm{p}$ value .009 . This study found that both the majority of the executive respondents, 85 , and the majority of first-line management respondents, 14 , perceived their organizational climate to be Rule. Thirty-five middle managers, not a majority, reported a perceived organizational ethical work climate type of Rule. Three first-line managers, six middle managers, and seven executive managers reported a perceived organizational ethical work climate type of Caring. Thirteen first-line managers, eight middle managers, and 17 executive managers reported a perceived organizational ethical work climate type of Law and Code. Two first-line managers and, two middle managers reported a perceived organizational ethical work climate type of Instrumental. One first-line manager, two middle managers, and 17 executive managers reported a perceived organizational ethical work climate type of Independent.

Lewin and Stephens (1994) state that post-conventional individuals are particularly likely to become leaders (Kohlberg et al., 1983), and, as leaders, have a special opportunity for organizational impact. Postconventional or principled individuals believe that principles outweigh specific rules and interests, and view principles as universal, generalizable, and compelling. Principled individuals are very much concerned with right and wrong and with the dignity of the individual. Therefore, principled CEOs, leaders at the highest levels, will establish a climate of ethicality throughout their organizations and develop policies and processes that embody principles of respect for the individual. They will attempt to prevent wrongs committed in the name of the organization and not merely crimes of the organization (Lewin and Stephens, 1994, p. 198). 
What should be noted is that the majority of the respondents were part of top management. A large majority of the respondents perceive their organization to be part of one of the more ethical climate types. D'Aquila (1997), as did Lewin and Stephens (1994), believes that top management sets the tone of the organization. This suggests that most top managers believe that their companies are striving to operate in an ethical manner.

This study supports D'Aquila (1997) and Lewin and Stephen's (1994) position that top management establishes the ethical tone of an organization. But ethical awareness needs to be reinforced by engaging top management in social and ethical audits of the company and by scheduling periodic seminars, which serve to maintain ethical thought processes.

Business educators should stress that successful corporate leaders establish a climate of ethicality in their organizations by developing policies and processes that embody principles of respect for all individuals. Students can experience this through role playing and other interactions and assignments.

\section{Finding Three}

A statistically significant relationship was found between the selected demographics (industry types and gender) and the moral reasoning ability of individual managers.

The regression analysis showed the strongest contributing factor to the variance in $\mathrm{P}$ scores was industry types $(B e t a=-1.827, \mathrm{p}<.05)$. The second strongest contributing factor was gender $($ Beta $=-5.735, \mathrm{p}<.05)$. The variables industry and gender explains only $4.6 \%$ of the variations in the dependent variable $\mathrm{P}$ score.

A reported $\mathrm{R}$ square of .023 for industry types, $\mathrm{F}=4.995$ and $\mathrm{p}$ value .026 . A reported $\mathrm{R}$ square for industry types and gender of $.046, \mathrm{~F}=5.057$ and $\mathrm{p}$ value .007 . The independent variables found a weak statistical significance. The variables industry and gender explains only $4.6 \%$ of the variations in the dependent variable $\mathrm{P}$ score.

No statistically significant relationship was found between an individual's locus of control, age, work tenure, management levels, education and the five ethical climate types to the moral reasoning ability of individual managers.

The implication of this finding is that managers or executive level employees should keep in mind that gender and the industry experience of a new employee might have an impact on his/her moral reasoning. However, age, work tenure, management levels, education, and the five ethical climate types may have no impact on his/her moral reasoning.

\section{Concluding Comments}

The value of ethical reasoning is that it is a premise upon which our country and our business enterprises are founded. High moral reasoning and the continued development of ethical standards are goals to which our government, businesses, and educational system must ascribe to.

Corporate America today must have higher ethics than ever before to ensure ethical soundness. They must accept responsibilities with respect to the environment; and that product safety and healthier working conditions must continue to improve as they have immensely improved in comparison to years past; and that racial and gender discrimination must continue to decrease. This is why it would be beneficial to understand as much as possible how ethical considerations impact on an organization's strategies and actions.

Dr. Almerinda Forte is an Associate Professor and Chairperson for the Division of Administration and Economics at St. John's University. She received her Ph.D. from New York University in 2001. Dr. Forte has presented papers at several Business Ethics Conferences and International Conferences. In addition to her teaching experience, Dr. 
Forte brings to the classroom her experiences from numerous companies, including Merrill Lynch, Pierce, Fenner and Smith and The New York State Society of CPA's.

Figure 1: Diagram of Research Variables

Independent Variables

Dependent Variables

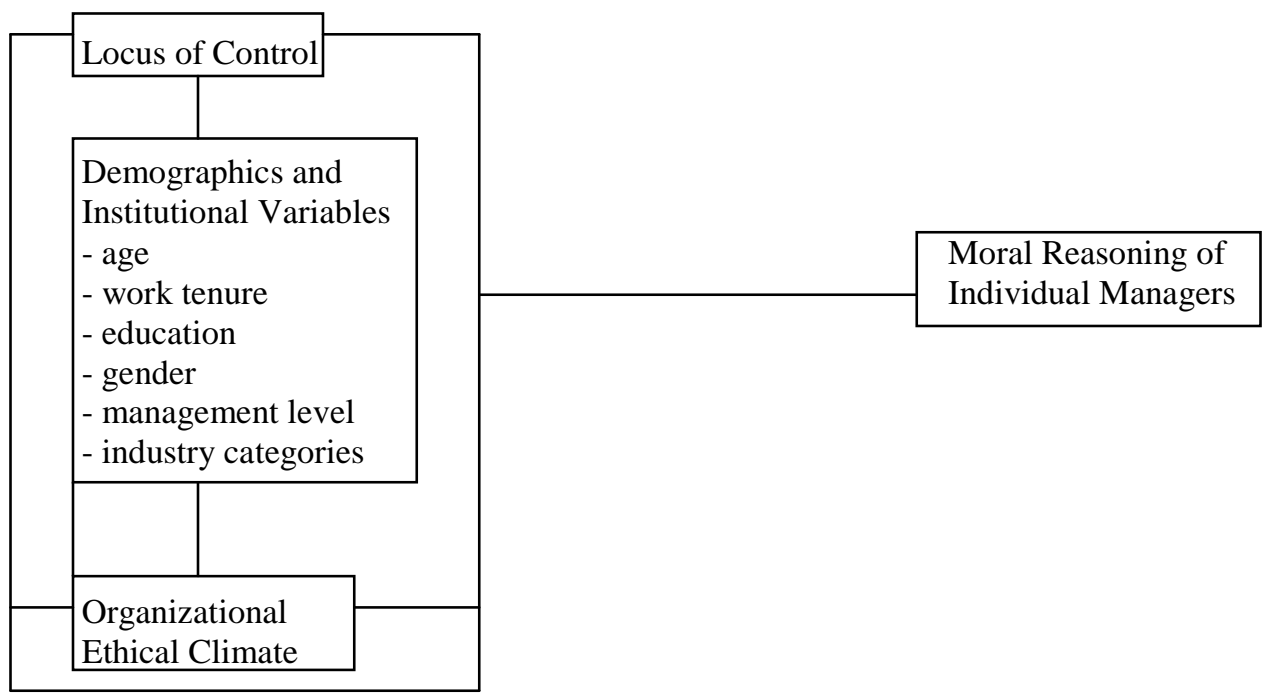

\section{References}

1. D’Aquila, J. (1997). Internal Control Environment Forces and Financial Reporting Decisions Made by Financial Accountants. Unpublished doctoral dissertation, New York University.

2. Dillman, D.A. (1978). Mail And Telephone Survey: The Total Design Method. New York, NY: John Wiley and Sons.

3. Dillman, D.A. (1999). Mail and Electronic Surveys, the Tailored Design Method. New York, NY: John Wiley \& Sons, Inc.

4. Kohlberg, L. (1981). The Psychology of Moral Development Volume One. Harper and Row.

5. Kohlberg, L. (1970). Moral Stages and Moralization. Moral development and behavior New York, N.Y.: Holt, Rinehart \& Winston.

6. Kohlberg, L. (1984). The Psychology of Moral Development Volume Two. San Francisco: Harper \& Row Publishers.

7. Kohlberg, L. (1969). Stage and sequence: the cognitive - developmental approach to socialization. Handbook of Socialization Theory and Research. Goslin D. (ed), Chicago, Rand McNally, pp 347-480.

8. Kohlberg, L. (1969). Stage and Sequence. Handbook of Socialization Theory and Research Chicago, IL: Rand McNally.

9. Kohlberg, L. (1976). Moral stages and moralization; the cognitive developmental approach. Moral Development and Behavior. Lickona, T. (ed). New York: Holt,Rinehart, \& Winston, pp 31-55.

10. Kohlberg, L. (1984). The Relationship of Moral Judgement To Moral Action, Morality, Moral Behavior and Moral Development. New York: John Wiley \& Sons.

11. Kohlberg, L. (1982). Essays On Moral Development: The Philosophy of Moral Development. San Francisco, CA: Harper \& Row.

12. Kohlberg, L. (1958). The Development of Modes of Moral Thinking and Choice in the Years 10 to 16. Unpublished Doctoral Dissertation, The University of Chicago. 
13. Kohlberg, L., Levine, C., and Hewer, A. (1983) Moral stages: a current formulation and a response to critics. Basel: Karger.

14. Lewin, A.Y., \& Stephens, C.U. (1994). CEO attitudes as determinants of organization design: An integrated model. Organization Studies, 15 (2), 183-212.

15. Litwin, G.H. a

16. nd Stringer, R.A. (1968). Motivation and Organizational Climate. Harvard Business School.

17. Mauro, N.J. (1987). Business Ethics, Managerial Decision Making, and Corporate Culture and Values. Unpublished doctoral dissertation, New York University.

18. McKenna, J.N. (1993). Ethical Dilemmas In Financial Reporting Situations and The Preferred Mode of Resolution of Ethical Conflicts As Taken By Certified and Noncertified Management Accountants In Organizations With Perceived Different Ethical Work Climates. Unpublished doctoral dissertation, New York University.

19. Rest, J.R. (1983). Morality. Handbook of Child Psychology, edited by P. Mussen, $4^{\text {th }}$ Edition, Vol. 3 on Cognitive Development, pp. 556-629. New York, NY: John Wiley and Sons.

20. Rest, J.R. (1979). Development In Judging Moral Issues. Minneapolis, Minnesota: University of Minnesota Press.

21. Rest, J.R. (1982, February). A psychologist looks at the teaching of ethics. Hastings Center Report pp. 2936

22. Rest, J.R. (1988). Why Does College Promote Development In Moral Judgement? Journal of Moral Education, 17 (3), 183-193.

23. Rest, J.R. and Narvaez, D. (1994). Moral development in the professions: Psychology and applied ethics. Hillsdale, N.J. Lawrence Erlbaum Association, Publishers.

24. Rest, J.R. (1986). Moral development: Advances in research and theory. New York, NY: Praeger Publishers. Katholieke Universiteit Levven, Belgium Doctoral Dissertation.

25. Rotter, J.B. (1966). Generalized expectancies for internal versus external control of reinforcement. Psychological Monographics, 80 (1), 1-28.

26. Rotter, J.B. (1982). The development and application of social learning theory: Selected papers. New York: Praeger.

27. Tagiuri, R. and Litwin, G.H. (1968) Organizational Climate, Exploration of a Concept. Harvard University Law School.

28. Victor, B. and Cullen, J. B. (1987). A theory and measure of ethical climate in organizations. Research In Corporate Social Performance and Policy 9, 51-71.

29. Victor, B., \& Cullen, J.B. (1988). The organizational basis of ethical work climates. Administrative Science Quarterly March, pp 101-125.

30. Wyld, D.C. (1993). An empirical test of selected aspects of the synthesis integrated model of ethical decision-making in business. Unpublished doctoral dissertation, Memphis State University. 